\title{
Time-dependent freezing rate parcel model
}

\author{
G. Vali and J. R. Snider \\ Department of Atmospheric Science, University of Wyoming, Laramie, Wyoming, USA \\ Correspondence to: G. Vali (vali@uwyo.edu) \\ Received: 3 October 2014 - Published in Atmos. Chem. Phys. Discuss.: 26 November 2014 \\ Revised: 22 January 2015 - Accepted: 27 January 2015 - Published: 25 February 2015
}

\begin{abstract}
The time-dependent freezing rate (TDFR) model here described represents the formation of ice particles by immersion freezing within an air parcel. The air parcel trajectory follows an adiabatic ascent and includes a period in time when the parcel remains stationary at the top of its ascent. The description of the ice nucleating particles (INPs) in the air parcel is taken from laboratory experiments with cloud and precipitation samples and is assumed to represent the INP content of the cloud droplets in the parcel. Time dependence is included to account for variations in updraft velocity and for the continued formation of ice particles under isothermal conditions. The magnitudes of these factors are assessed on the basis of laboratory measurements. Results show that both factors give rise to three-fold variations in ice concentration for a realistic range of the input parameters. Refinements of the parameters specifying time dependence and INP concentrations are needed to make the results more specific to different atmospheric aerosol types. The simple model framework described in this paper can be adapted to more elaborate cloud models. The results here presented can help guide decisions on whether to include a time-dependent ice nucleation scheme or a simpler singular description in models.
\end{abstract}

\section{Introduction}

While it is widely recognized that the formation of ice is a major factor in the evolution of many tropospheric clouds and in the formation of precipitation, formulations of ice nucleation in cloud models are still tentative. Three main reasons for this can be identified. First, a proven theoretical underpinning of heterogeneous ice nucleation is missing. This problem is unlikely to be resolved within the foreseeable future due to the lack of tools to study ice nucleation processes on the scale of embryo formation. Second, the large spatial, temporal, and compositional variability of atmospheric aerosols, and of the subset of ice nucleating particles (INPs), makes generalizations difficult. This difficulty has been well documented in the literature because it is a problem for other aspects of cloud and climate models as well. Third, parameterizations of available laboratory results on ice nucleation have taken a number of diverging paths, with relatively weak support for each. There is agreement however that, for lowand mid-tropospheric clouds, immersion freezing is the dominant mode of ice nucleation (e.g., Lohmann and Diehl 2006; Murray et al., 2010; Eidhammer et al., 2010; de Boer et al., 2011; IPCC 2013, page 604).

Since there are so many elements and so many unknowns in how ice nucleation takes place in clouds, essentially all cloud, weather and climate models turn to parametric solutions. Much effort is being dedicated to testing various forms of parameterizations, mostly by evaluating the results in terms of observed ice concentrations or other cloud properties (e.g., Barahona and Nenes, 2011; Morales et al., 2012; Zhang et al., 2013; English, 2014; Peng et al. 2014). Based on strong evidence, all forms of the parameterization treat ice nucleation as a function of temperature. This is done with either the number of ice nucleation events or their rate per unit time as the starting point. The former path leads to ice nucleation as a function of temperature, but not of time, and has its roots in the singular description of ice nucleation, whereas the latter adds time dependence and is based on the stochastic description of ice nucleation. While the difference in these two approaches appears to be subtle, they can lead to rather different results, depending on the time evolution of the cloud. The difference is specially significant for clouds in which air parcels rise to a nearly steady height and remain there for some period of time. Stratocumulus and altocumulus are two examples of special relevance. 
Measurements of the abundance of INPs in the atmosphere using cloud chamber instruments of various designs provide the basis for formulae dependent on temperature (e.g., Meyers et al., 1992; Prenni et al., 2007), but these measurements provide limited information regarding the time element. Overall aerosol concentration or the abundance of some specific aerosol type (e.g., mineral dust), threshold size or particle surface area have been included as additional parameters in newer parameterizations ( $\mathrm{Li}$ and Penner, 2005; Chen et al., 2008; Phillips et al., 2008; Muhlbauer and Lohmann, 2009; Diehl and Wurzler, 2010; DeMott et al., 2010; Eidhammer et al., 2010; Wang and Knopf, 2011; Phillips et al., 2012; Niemand et al., 2012; Hiranuma et al., 2014; Peng et al., 2014; Paukert and Hoose, 2014).

Stochastic formulations arise from the incorporation of classical nucleation theory (CNT) to define the dependence of ice nucleating ability on the physical and chemical properties of the INPs. Time dependence arises from CNT because it is expressed as the rate of nucleation per unit time. Examples of this approach are Khvorostyanov and Curry (2000), Diehl and Wurzler (2004), Hoose (2010), Wang and Knopf (2011), Yang et al. (2013), Wang et al. (2014), and Niedermeier et al. (2014).

The contrasting approaches to modeling ice nucleation in clouds is ascribable, to a great extent, to conflicting results from laboratory measurements. Vali (2014) argues that those conflicts are actually the result of imposed interpretations of the laboratory measurements. While many important questions remain, there is some convergence of evidence that neither the singular nor the stochastic descriptions represent adequately the process of immersion freezing nucleation. The dominant influence of the nucleating sites resident on the INP is recognized and models have been constructed to combine that dependence with the time dependence that follows from molecular fluctuations in nucleation (Vali, 1994; Wright and Petters, 2013; Herbert et al., 2014). The Vali (1994) results are confirmed and reinforced by the more recent work in Wright et al. (2013) and are given at least partial support in Herbert et al. (2014).

This paper presents an implementation of the laboratory results of Vali (1994) in an adiabatic parcel model called the time-dependent freezing rate (TDFR) model. The model allows the impact of time dependence to be explored for different INP and cloud scenarios. Laboratory measurements with water samples, as those of Vali (1994), have the advantage of direct observations of the time dependence of ice nucleation. Thus, this aspect of the model has a solid foundation within the limits of available data. On the other hand, use of these data for deriving ice particle formation in clouds has the drawback of leaving aside the factors that influence aerosolto-cloud transfer processes. The model is most informative with respect to how time variations influence ice nucleaation in addition to temperature.

The TDFR results show that ice particle concentrations vary three-fold with varying updraft velocities and that un- der isothermal conditions ice concentrations increase by factors of up to 3 above the values predicted on the basis of the singular description. In contrast, for isothermal conditions, the stochastic description leads to overestimates compared to either the singular description or the TDFR model.

\section{Formulation of the TDFR model}

The model is formulated for a parcel that rises at a constant velocity and then comes to a stable level at the top of its ascent. The parcel is assumed to retain adiabatic properties and there is no fallout of hydrometeors from the parcel. This scenario is a rough approximation for stratocumulus or altostratus clouds. It is a simple assumption that is useful for demonstrating the essential features of the TDFR model.

Initial conditions are in terms of cloud base temperature and pressure, and the assumed updraft velocity. Pressure, temperature and saturation vapor pressure are calculated for every $20 \mathrm{~m}$ of rise. Liquid water content is the difference between vapor content at cloud base vs. that at altitude. The three main elements of the nucleation model are (i) the nucleus spectra, (ii) the influence of updraft velocity on freezing rate and (iii) the freezing rate after cooling ceases. Immersion freezing is the only mode of ice nucleation considered. The mechanism of entry of the INPs into the cloud droplets is not treated and it is assumed that cloud droplets contain either zero or one INP. This assumption of no multiple INPs per drop is justified by the large ratio between the numbers of cloud droplets and ice particles.

In order to keep focus on the essential features of the model, the concentration of INPs in liquid is a specified model input and the cloud liquid water content $(L)$ is used to convert this concentration to one with reference to a volume of cloudy air.

\subsection{Nucleus spectra}

Characterization of the abundance of INPs is usually expressed in terms of number concentration as a function of temperature, often referred to as nucleus spectra. Depending on the method used to obtain that function, the nucleus spectrum can take one of two forms. The INP number concentration is expressed per unit volume of air if INPs are detected using cloud chambers of varying designs (e.g., DeMott et al., 2011) or with filter samples of the atmospheric aerosol. For INPs suspended in liquid water samples of cloud droplets or of precipitation, it is expressed per unit volume of liquid (e.g., Vali, 1971; Wright and Petters, 2013).

Numerous and varied experimental methods have clearly established that the number of INPs increases rapidly at temperatures decreasing below $0^{\circ} \mathrm{C}$ until the homogeneous nucleation threshold near $-35^{\circ} \mathrm{C}$. This general rule holds equally for samples of air, for precipitation samples or for prepared aerosol or hydrosol samples with specific sub- 
stances. Analytically the spectra are most frequently represented by an exponential formula with empirically determined constants. One disadvantage of this formulation is that, without a specific range of validity being stated, it indicates a finite number of INPs even at $0{ }^{\circ} \mathrm{C}$, and that is not physically reasonable. A power-law formula avoids this problem and can better represent the very low number of INPs active at just a few degrees below $0{ }^{\circ} \mathrm{C}$. Taking into account the imprecisions of the measurements, the two formulae provide equally good fits over a relatively small temperature range. For simplicity, power-law formulas are used in this work, but any other analytic or numerical form could be used without any difficulty. The general form of the equation for the concentration of INPs, with $T$ in ${ }^{\circ} \mathrm{C}$ and using $-10^{\circ} \mathrm{C}$ as the reference value, is

$$
K(T)=A \times\left(\frac{T}{-10}\right)^{B}
$$

and its derivative with respect to supercooling $(-T)$

$k(T)=0.1 \times A \times B \times\left(\frac{T}{-10}\right)^{B-1}$.

$K(T)$ is usually given in the literature per unit volume of water, and hence the dimension of the constant $A$ is, in cgs units, $\mathrm{cm}^{-3}$. In this paper $K(T)$ is given per unit mass of water, $\mathrm{g}^{-1}$, with no change in the numerical value of $A$ since the density of water is $1 \mathrm{~g} \mathrm{~cm}^{-3}$. The constant $B$ is dimensionless ${ }^{1}$.

The specific formulae used here are taken from the analysis of cloud and precipitation samples. One example is that given in Vali (1978, Fig. 4) for summer rain over Colorado, USA. The other is an approximate mean for a number of cloud water samples captured at the summit of the Puy de Dome, France, as reported by Joly et al. (2014). These two formulae are designated as V78 and J14 and express the number of INPs active above a given temperature $T$ in ${ }^{\circ} \mathrm{C}$ :

$K_{\mathrm{V} 78}(T)=12 \times\left(\frac{T}{-10}\right)^{6.2}$

and

$K_{\mathrm{J} 14}(T)=13 \times\left(\frac{T}{-10}\right)^{6.8}$.

As can be seen, these formulae do not contain any dependence on time. $K_{\mathrm{V} 78}$ was determined at a cooling rate of $1{ }^{\circ} \mathrm{Cmin}^{-1}$, while the $K_{\mathrm{J} 14}$ data were obtained with stepwise cooling, which is roughly equivalent to an average cooling rate of $0.1^{\circ} \mathrm{Cmin}^{-1}$. To normalize the two data sets, a correction was applied to $K_{\mathrm{J} 14}$ as per Eq. (5) of Sect. 2.2. In the following, both $K_{\mathrm{V} 78}$ and $K_{\mathrm{J} 14}$ will be applied as valid for the same cooling rate of $1^{\circ} \mathrm{C} \mathrm{min}-1$.

\footnotetext{
${ }^{1} \mathrm{~A}$ list of symbols is given at the end of the text.
}

Even though the functions $K(T)$ have been normalized by cooling rate, they are still expressed in terms of the singular description. It may be remarked that this type of normalization for cooling rates in general makes comparisons between data obtained with different methods more meaningful. Further insight into the meaning of the singular description can be found in Murray et al. (2012), Vali (2014) and Sear (2014).

It should also be noted that the effects of solutes are ignored; those effects are significant at the early stages of condensation when the concentrations of dissolved salts are high. In the simulations here reported, the cloud parcels are considered when located well above cloud base height, and hence the solute effect has a negligible impact on the results.

\subsection{Nucleation during cooling}

Assuming a closed-parcel adiabatic ascent, the rate of cooling varies only moderately with pressure (Curry and Webster, 1998; their Table 6.1). However, since the updraft velocity can vary by an order of magnitude or more under different circumstances, and since the rate of cooling changes in proportion to the updraft velocity, the effect of the updraft on the freezing rate needs to be accounted for.

Empirical data on the cooling-rate dependence of freezing nucleation are available from a few laboratory measurements (Vali and Stansbury, 1966; Bradley et al., 2012; Wright et al., 2013; Knopf and Alpert 2013; Wright and Petters, 2013; Herbert et al., 2014). Evidence clearly shows that freezing temperatures shift to lower temperatures with increasing cooling rates. This finding is consistent with the notion that nucleation requires the assembly of an embryo of critical size, and if less time is available at a given temperature, the likelihood of the nucleation event is decreased. The magnitude of this effect is relatively minor but not negligible. It can be expressed, for example, in terms of the shift in the mean freezing temperature of a sample and it is assumed that this is representative of the shift of the entire $K(T)$ spectrum along the temperature scale. According to the laboratory data cited above, the temperature shift can be given as

$\Delta T=-\xi \times \ln \left(\frac{w}{w_{0}}\right)$,

where $\Delta T$ is the shift in temperature for a given concentration, $K(T)$ or $k(T)$, to be reached, $w$ is the cooling rate and $w_{0}$ is a reference value with respect to which the temperature shift is being determined. The value of the constant $\xi$ has been found to range from 0 to $\sim 1$ for different samples. Experiments with the largest number of tests are those with distilled water (Vali and Stansbury, 1966) and with suspensions of Arizona Test Dust (ATD) (Wright ant Petters, 2013). Values of $\xi$ from these tests are 0.33 and 0.29 , respectively. A value $\xi=0.3$ is adopted for this paper. Wright et al. (2013) show that there is little variation in $\xi$ for a large range of different INPs. Knopf and Alpert (2013) derived values of $\xi=0.2$ to 1.3 for different materials. Herbert et al. (2014) 
also suggest that the value of $\xi$ is dependent on the composition of the INPs. In any case, if important variations are identified, species-specific values of $\xi$ can be included in the model, weighted by the proportions of different INPs.

\subsection{Nucleation at constant temperature}

Data on freezing rates at constant supercooled temperatures are scant and somewhat contradictory, as discussed in Sect. 3.2.2 of Vali (2014). Here we adopt the results presented in Vali (1994). Measurements presented there show that the freezing rate decreases with time after the moment that cooling stops according to the relationship

$R(t) \equiv \frac{\delta n}{\delta t}=R_{\mathrm{S}} \times p \times e^{-q \times t}$,

where time $t$ is counted from the arrival of the parcel at the isothermal level $\left(T_{S}\right), p$ and $q$ are constants, and $R_{\mathrm{S}}$ is the freezing rate in the temperature interval just before cooling stopped, given by

$R_{\mathrm{S}}=\frac{n_{s}-n_{(\mathrm{s}-\delta t)}}{\delta t}=k\left(T_{s}-\Delta T\right) \times w$,

using $n_{s}$ to designate the number of nucleation events per unit mass of cloud water that have taken place by the time the parcel reaches the isothermal level $T_{s}, n_{(\mathrm{s}-\delta t)}$ is the number at a small increment of time $\delta t$ prior to that, and $w$ is the rate of cooling at that time.

The values of the constants $p_{1}=0.46$ and $q_{1}=$ $0.23 \mathrm{~min}^{-1}$ were determined (Vali, 1994) for distilled water and for $-20^{\circ} \mathrm{C} \leq T_{s} \leq-16^{\circ} \mathrm{C}$, using a cooling rate of $w=1{ }^{\circ} \mathrm{Cmin}^{-1}$. A re-analysis of those data yielded the slightly different values used in this work: $p_{1}=0.32$ and $q_{1}=0.23 \mathrm{~min}^{-1}$. For other temperatures and for other rates of cooling, the following assumptions are made: (i) the value of $p$ remains the same for all cooling rates, $p_{w}$, (ii) by the end of the isothermal time period, $t_{\mathrm{s}}$, the number of freezing events is independent of the rate $w$ at which $T_{s}$ was reached, and (iii) the composition of the INPs does not influence the process beyond what is already incorporated into the $k(T)$ function in Eq. (2). The first assumption is made due to the lack of more detailed data. The second assumption follows, in an intuitive way, from the argument that the isothermal time period allows for all nucleation events to take place that were retarded during a fast rate of cooling. Conversely, fewer events during that time compensate for larger number of events that accompany a slow rate of cooling. This assumption is also the simplest one that can be made at this time, pending further data. The third assumption is also forced by the lack of data. Clearly, all three assumptions will need to be tested in future experiments.

Since $R_{\mathrm{S}}$ is dependent on $w$ (cf. Eq. 7), the first two assumptions can only be satisfied if $q_{w}$ is calculated as a function of $w$ using the empirical value of $q_{1}=0.23 \mathrm{~min}^{-1}$ to predict the total number of freezing events during the isothermal interval of duration $t_{\mathrm{s}}$. Equating the integrals of Eq. (6) for both $w=1{ }^{\circ} \mathrm{Cmin}^{-1}$ and for the actual $w$, for time periods long enough to have $R(t)$ reach negligible values, leads to

$q_{w}=q_{1} \times \frac{p_{w}}{p_{1}} \times \frac{R_{\mathrm{s}, \mathrm{w}}}{R_{\mathrm{S}, 1}}=q_{1} \times \frac{p_{w}}{p_{1}} \times \frac{k\left(T_{s}-\Delta T\right) \times w}{k\left(T_{s}\right) \times w_{0}}$,

where the second subscripts on $R_{\mathrm{S}}$ refer either to cooling at rates of $w=1{ }^{\circ} \mathrm{Cmin}^{-1}$, for which $q_{1}$ has been measured, or to some other value of $w$. Once the value of $q_{w}$ has been determined, the application of Eq. (6) allows the freezing rate to be calculated for any point in time after the arrival at the isothermal condition.

The solution described in the foregoing allows $q_{w}$ to be determined from a series of model runs for various desired cloud conditions defined by different values of $T_{S}$ and $w$. The results are given in Table 1 and show that the major sensitivity of $q_{\mathrm{w}}$ is to the updraft velocity, $v_{\text {up }}$. This occurs because the product of the updraft velocity and the temperature lapse rate determines the cooling rate $w$ and because $q_{\mathrm{w}}$ is proportional to $w$ in Eq. 8 .

However, it is to be noted that both $p_{\mathrm{w}}$ and $q_{\mathrm{w}}$ can be expected to be dependent on the magnitude and specific form of $K(T)$. The latter is expected to be manifested as a dependence on the slope of the $K(T)$ at $T_{\mathrm{s}}$, i.e., the differential nucleus spectrum $k\left(T_{\mathrm{S}}\right)$ (Vali, 1971).

\subsection{The TDFR model}

The number of ice particles in the cloud parcel at any time during the ascent is dependent on the cooling rate during the parcel's ascent. Expressions can be readily written for the number of nucleation events in the cloud water and for concentration of ice particles at the end of the ascent, $n_{s}$ and $N_{s}$, using $w_{0}=1{ }^{\circ} \mathrm{Cmin}^{-1}$, as

$n_{s}=K\left(T_{\mathrm{s}}-\Delta T\right)=K\left(T_{s}+\xi \times \ln w\right)$

and

$N_{s}=n_{s} \times L_{s}$,

where the value of $w$ is determined by the updraft and the concurrent lapse rate.

The number of nucleation events at the isothermal level increases beyond $n_{s}$ and $N_{s}$. The magnitude of this increase is such that after a long period the total concentration of ice particles approaches the value $N_{\text {tdfr }}$ that is derived, in accordance with assumption (ii) given in Sect. 2.3, from the case with $w=w_{0}=1^{\circ} \mathrm{C} \mathrm{min}^{-1}$. The increase, $\Delta n_{0}$, is given by the integral of Eq. (6). To obtain this value, Eq. (7) is substituted for $R_{\mathrm{S}}$, the cooling rate is set to the base value $w=w_{0}$ so that $\Delta T=0$, and the integral is carried from the beginning of the isothermal period to a time long enough to have the freezing rate become negligible. The result is

$\Delta n_{0}=\int_{0}^{\infty} R(t) \times \mathrm{d} t=k\left(T_{S}\right) \times \frac{p_{1}}{q_{1}} \times w_{0}$. 
Table 1. Ice particle concentrations obtained with the TDFR model under different initial conditions. Symbols stand for the following: $K(T)$ is the nucleus spectrum given by either Eqs. (3) or (4); $p_{\mathrm{cb}}$ and $T_{\mathrm{cb}}$ define cloud base conditions; $v_{\mathrm{up}}$ is the assumed updraft velocity; $T_{S}$ is the temperature, $N_{S}$ is the ice concentration and $w$ is the cooling rate when the parcel reaches the isothermal level; $q_{w}$ is the value of the decay constant of the freezing rate from Eq. (8); $N_{\mathrm{tdfr}}$ is the asymptotic value of the ice concentration for the isothermal period; $r_{t}=\frac{N_{\mathrm{tdfr}}}{N_{s}}$; $N_{\text {sing }}$ is the ice concentration predicted by a singular interpretation of $K(T) ; r_{S}=\frac{N_{\mathrm{tdfr}}}{N_{\mathrm{sing}}}$; and $t_{90}$ is the time after arrival at the isothermal level for $90 \%$ of the asymptotic ice concentration to be reached.

\begin{tabular}{|c|c|c|c|c|c|c|c|c|c|c|c|c|c|}
\hline $\begin{array}{l}\text { Run } \\
\text { no. }\end{array}$ & $K(T)$ & $\begin{array}{c}p_{\mathrm{cb}} \\
\mathrm{mb}\end{array}$ & $\begin{array}{l}T_{\mathrm{cb}} \\
{ }^{\circ} \mathrm{C}\end{array}$ & $v_{\text {up }} \mathrm{m}^{-1}$ & $\begin{array}{l}T_{S} \\
{ }^{\circ} \mathrm{C}\end{array}$ & $\begin{array}{c}w \\
{ }^{\circ} \mathrm{Cmin} \\
-1\end{array}$ & $\begin{array}{c}N_{S} \\
\mathrm{~m}^{-3}\end{array}$ & $\begin{array}{c}q w \\
\min ^{-1}\end{array}$ & $\begin{array}{l}N_{\mathrm{tdfr}} \\
\mathrm{m}^{-3}\end{array}$ & $r_{t}$ & $\begin{array}{l}N_{\text {sing }} \\
\mathrm{m}^{-3}\end{array}$ & $r_{s}$ & $\begin{array}{l}t_{90} \\
\min \end{array}$ \\
\hline 1 & Eq. (3) & 700 & 2.0 & 0.4 & -6 & 0.15 & 1.55 & 0.12 & 2.12 & 1.37 & 0.88 & 2.42 & 72 \\
\hline 2 & Eq. (3) & 700 & 2.0 & 2.0 & -6 & 0.73 & 0.96 & 0.20 & 2.12 & 2.20 & 0.88 & 2.42 & 21 \\
\hline 3 & Eq. (3) & 700 & 2.0 & 10 & -6 & 3.7 & 0.58 & 0.48 & 2.12 & 3.67 & 0.88 & 2.42 & 6.7 \\
\hline 4 & Eq. (3) & 700 & 2.0 & 0.4 & -10 & 0.15 & 37.6 & 0.090 & 49.7 & 1.32 & 26.8 & 1.86 & 98 \\
\hline 5 & Eq. (3) & 700 & 2.0 & 2.0 & -10 & 0.77 & 28.1 & 0.20 & 49.7 & 1.77 & 26.8 & 1.86 & 25 \\
\hline 6 & Eq. (3) & 700 & 2.0 & 10 & -10 & 3.85 & 20.7 & 0.56 & 49.7 & 2.40 & 26.8 & 1.86 & 6.8 \\
\hline 7 & Eq. (3) & 700 & 2.0 & 0.4 & -14 & 0.16 & 305 & 0.08 & 388 & 1.27 & 240 & 1.62 & 122 \\
\hline 8 & Eq. (3) & 700 & 2.0 & 2.0 & -14 & 0.80 & 247 & 0.20 & 388 & 1.57 & 240 & 1.62 & 30 \\
\hline 9 & Eq. (3) & 700 & 2.0 & 10 & -14 & 4.02 & 198 & 0.65 & 388 & 1.95 & 240 & 1.62 & 7.1 \\
\hline 10 & Eq. (4) & 700 & 2.0 & 0.4 & -10 & 0.15 & 42.3 & 0.094 & 56.5 & 1.34 & 29.1 & 1.94 & 98 \\
\hline 11 & Eq. (4) & 700 & 2.0 & 2.0 & -10 & 0.77 & 30.7 & 0.20 & 56.5 & 1.84 & 29.1 & 1.94 & 25 \\
\hline 12 & Eq. (4) & 700 & 2.0 & 10 & -10 & 3.85 & 22.0 & 0.55 & 56.5 & 2.57 & 29.1 & 1.94 & 6.8 \\
\hline 13 & Eq. (4) & 700 & 2.0 & 2.0 & -6 & 0.73 & 0.78 & 0.20 & 1.80 & 2.31 & 0.70 & 2.56 & 21 \\
\hline 14 & Eq. (4) & 700 & 2.0 & 2.0 & -14 & 0.80 & 32.9 & 0.20 & 533 & 1.62 & 318 & 1.68 & 29 \\
\hline 15 & Eq. (3) & 850 & 10.0 & 2.0 & -6 & 0.74 & 2.36 & 0.20 & 5.17 & 2.19 & 2.15 & 2.41 & 34 \\
\hline 16 & Eq. (3) & 850 & 10.0 & 2.0 & -10 & 0.77 & 52.4 & 0.20 & 92.8 & 1.77 & 49.8 & 1.86 & 37 \\
\hline 17 & Eq. (3) & 850 & 10.0 & 10 & -6 & 3.68 & 1.42 & 0.48 & 5.17 & 3.63 & 2.15 & 2.40 & 9.2 \\
\hline 18 & Eq. (3) & 850 & 10.0 & 10 & -10 & 3.86 & 38.5 & 0.56 & 92.8 & 2.41 & 49.8 & 1.86 & 9.3 \\
\hline 19 & Eq. (3) & 500 & -5.0 & 2.0 & -10 & 0.74 & 9.85 & 0.19 & 17.3 & 1.76 & 9.3 & 1.86 & 15 \\
\hline 20 & Eq. (3) & 500 & -5.0 & 2.0 & -14 & 0.77 & 122 & 0.19 & 190 & 1.56 & 118 & 1.61 & 20 \\
\hline 21 & Eq. (4) & 500 & -5.0 & 2.0 & -10 & 0.74 & 10.8 & 0.19 & 19.6 & 1.83 & 10.1 & 1.94 & 15 \\
\hline 22 & Eq. (3) & 500 & -5.0 & 0.4 & -10 & 0.15 & 13.2 & 0.089 & 17.3 & 1.31 & 9.3 & 1.86 & 49 \\
\hline 23 & Eq. (3) & 500 & -5.0 & 0.4 & -14 & 0.15 & 151 & 0.080 & 190 & 1.26 & 118 & 1.61 & 75 \\
\hline 24 & Eq. (4) & 500 & -5.0 & 0.4 & -10 & 0.15 & 14.8 & 0.093 & 19.6 & 1.32 & 10.1 & 1.94 & 49 \\
\hline
\end{tabular}

The total concentration of ice particles is given by the liquid water content at $T_{S}$ times the sum of $n_{s}$ from Eq. (9) and $\Delta n_{0}$ from Eq. (11):

$N_{\mathrm{tdfr}}=\left[K\left(T_{S}\right)+k\left(T_{S}\right) \times \frac{p_{1}}{q_{1}} \times w_{0}\right] \times L_{S}$,

which for $K_{\mathrm{V} 78}$ from Eq. (3) and with $w_{0}=1^{\circ} \mathrm{Cmin}^{-1}$ yields

$$
\begin{aligned}
& N_{\mathrm{tdfr}}=\left[12 \times\left(\frac{T_{S}}{-10}\right)^{6.2}+7.44 \times\left(\frac{T_{S}}{-10}\right)^{5.2}\right. \\
& \left.\times \frac{0.32}{0.23} \times 1.0\right] \times L_{s} .
\end{aligned}
$$

Equations (12) and (13) represent an asymptotic value that is approached exponentially from $N_{s}$. When cooling ceases, the rate of approach is $R_{S}$ (Eq. 7), and this subsequently decreases (Eq. 6). The time to reach $90 \%$ of the final value is included in Table 1 for each case.

\section{Simulation results}

The main features of the TDFR model can be illustrated with the example shown in Fig. 1. The time evolution of ice particle concentration is shown in this figure for a cloud parcel that rises from $+2{ }^{\circ} \mathrm{C}, 700 \mathrm{mb}$ to $-10^{\circ} \mathrm{C}$ with three different assumed updraft velocities. The input concentration of INPs is taken to be that given by the $K_{\mathrm{V} 78}$ spectrum. Portions of the plotted lines with symbols show the increase in ice concentration during the ascent. This portion of the process terminates with concentrations indicated by heavy horizontal lines. The subsequent increases in ice concentrations, while the parcel is assumed to remain isothermal, are represented by the segments above these line segments. The cloud liquid water content at $-10^{\circ} \mathrm{C}$ in all three cases is the same.

As seen in Fig. 1, the TDFR model leads to two notable results. First, the number of ice particles at the time of arrival at the isothermal level differs for the different updraft velocities; higher values correspond to slower updraft velocities. Second, ice concentrations during the isothermal period continue to increase; the largest increase is found for the high 


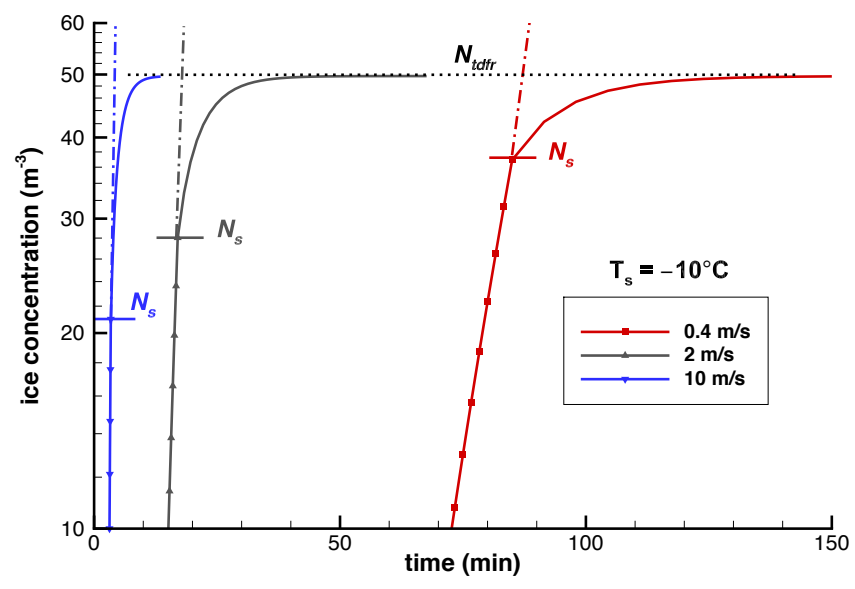

Figure 1. Time evolution of ice particle concentration in a parcel of air undergoing lifting at three different updraft velocities. Cloud base is at $700 \mathrm{mb}$ and $+2^{\circ} \mathrm{C}$. Lifting stops at $-10^{\circ} \mathrm{C}$ and the parcel remains at that level. The TDFR model is initialized with an INP concentration given by Eq. (3). The horizontal line segments at $N_{S}$ indicate the ice concentrations when the lifting stops. Note that the greater the updraft velocity is, the lower the value of $N_{S}$ is. $N_{\mathrm{tdfr}}$ is the asymptotical value of ice concentration while the parcel is at $-10^{\circ} \mathrm{C}$.

updraft velocity case. The increase at the steady temperature is due entirely to the time dependence of the nucleation process. No new INPs are assumed to enter the cloud parcel; that process is not considered here.

Results of the same simulations, plotted as a function of temperature, are given in Fig. 2. Slower updrafts lead to higher ice concentration at the same temperature, but the difference is reduced with time after reaching the isothermal level.

For the same assumed conditions as those for Figs. 1 and 2 , the singular description (with no time dependence) would have led to the same number of ice particles at all times, independent of updraft velocity. For the final temperature $T_{s}=-10^{\circ} \mathrm{C}$ and $2.1 \mathrm{~g} \mathrm{~m}^{-3}$ liquid water content, Eq. (3) yields $N_{\text {sing }}=2.1 \times 12 \times 1.0 \approx 25 \mathrm{~m}^{-3}$ for $K_{\mathrm{V} 78}$. If time dependence is assumed to follow the stochastic assumption, the rate of freezing would be constant throughout the isothermal period at a value equal to that when the parcel first arrives at that level. The resulting increases in ice concentrations are shown in Fig. 1 with dash-dot lines. Clearly, for isothermal conditions, the stochastic assumption can lead to orders of magnitude greater ice concentrations with time than either the singular or TDFR models.

In order to assess the range predictions of the TDFR model, simulations were made for varying cloud base conditions, for the two spectra given in Eqs. (3) and (4), and for different top temperatures. The results are summarized in Table 1 .

The data in Table 1 lead to the following observations.

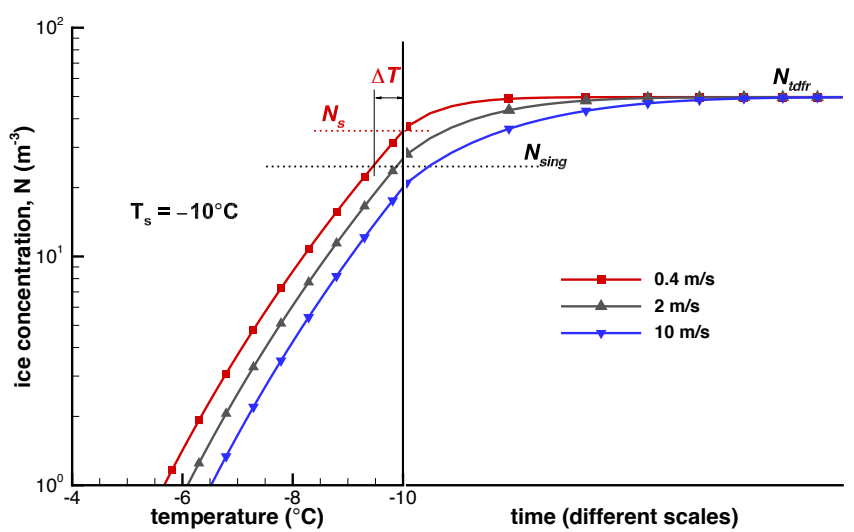

Figure 2. The same data as in Fig. 1 displayed as a function of temperature during the lifting of the parcel and as a function of time after that. Timescales differ for the three cases. $N_{S}$ and $\Delta T$ are indicated for $0.4 \mathrm{~m} \mathrm{~s}^{-1}$ updraft velocity. $\Delta T$ is defined in Eq. (5) with $w=0.15^{\circ} \mathrm{C} \mathrm{min}^{-1}$ for this case. $N_{\text {sing }}$ is the ice concentration from Eq. (3) for $-10^{\circ} \mathrm{C}$ using the singular description.

1. As expected, colder temperatures lead to higher ice concentrations for similar conditions. In addition, due to estimating the concentration of ice particles in the air parcel from laboratory measurements of nucleation in water samples, ice concentration is proportional to cloud liquid water content in these simulations. That relationship is likely not to be strictly valid in general.

2. For the same cloud base conditions, the faster updrafts lead to lower ice concentrations when arriving at the isothermal level. For example, runs 4,5 and 6 have $N_{s}=38,28$ and 21 ice particles per $\mathrm{m}^{3}$ of air. This is due to the shorter time available for nucleation to take place, as discussed in Sect. 2.2.

3. The value of $N_{s}$ is larger or smaller than $N_{\text {sing }}$, depending on the value of $w$ in comparison with $1^{\circ} \mathrm{Cmin}^{-1}$ in Eq. (9).

4. The value of $N_{\mathrm{tdfr}}$ relative to the ice concentration when the parcel arrives at the isothermal level $\left(N_{S}\right)$ is in the range $r_{t}=1.26$ to 3.67 . Compared to the singular interpretation of $K(T)$ (no time dependence), the TDFR model yields ice concentrations that are factors of $r_{s}=$ 1.61 to 2.56 higher.

5. The ratio $r_{t}=\frac{N_{\mathrm{tdfr}}}{N_{s}}$ is most strongly dependent on the updraft velocity and secondarily on $T_{s}$. This can be seen in the values in Table 2 .

6. For given input spectrum $K(T)$, the ratio $r_{s}=\frac{N_{\mathrm{tdfr}}}{N_{\text {sing }}}$ depends only on $T_{s}$. For $T_{s}=-6,-10$ and $-14{ }^{\circ} \mathrm{C}$, the values of $r_{s}$ are 2.42, 1.86 and 1.61 (neglecting differences of about $1 \%$ that result from using the same finite integration time for all cases). 
Table 2. Values of the ratio $r_{t}=\frac{N_{\mathrm{tdfr}}}{N_{s}}$ from Table 1 for three values of the updraft, $v_{\text {up }}$.

\begin{tabular}{cc}
\hline$v_{\text {up }}$ & $r_{t}$ \\
\hline 0.4 & 1.26 to 1.37 \\
2.0 & 1.56 to 1.77 \\
10.0 & 1.95 to 3.7 \\
\hline
\end{tabular}

7. Both of the preceding two points refer to concentration ratios at the asymptotic limit; for shorter time intervals at $T_{S}$, the ratios would be smaller. The stated ratios are conditioned by the assumption made here that the values of $\xi, p$ and $q$ in Eqs. (5) and (6) are independent of temperature and of the nature of the INPs. Also, the values are all taken from simulations with the only two sets of assumed input concentration of INPs, $K_{\mathrm{V} 78}$ and $K_{\mathrm{J} 14}$.

8. The time needed for the isothermal increases in ice concentration to take place is linked, in these calculations, to the updraft-dependent value just before arrival at the isothermal level. That aspect of the model (see Sect. 2.3) can be improved when more laboratory results allow Eq. (6) to be replaced by a better expression, or when $p$ and $q$ are evaluated for INPs of different materials. The final ice concentration, $N_{\mathrm{tdfr}}$, is not affected by this timescale.

9. The ratios $r_{t}$ and $r_{s}$ are not large compared to the atmospheric variability of INP concentrations, but the process they represent does call attention to the fact that, even at a given temperature, the ice concentrations increase with time. This time dependence should be taken into account when interpreting measurements in clouds, and in cloud models.

\section{Conclusions}

The TDFR model demonstrates that the time dependence of ice nucleation can be taken into account within cloud models in a relatively simple manner. The model is constructed on the basis of laboratory measurements of immersion freezing during steady cooling and with constant temperatures. The main point that can be derived from the analysis is that taking into account the time dependence of immersion freezing nucleation leads to higher ice concentrations than the timeindependent singular model. On the other hand, the stochastic description produces a large overestimate for clouds that remain isothermal for a period of time. Thus, it seems clear that of the two approaches most frequently used in cloud models to represent immersion freezing, the stochastic description can be more misleading than the singular description. For cloud parcels in which the temperature is monoton- ically lowered the difference is less evident, but if there are isothermal periods involved the difference becomes striking and can lead to grossly erroneous predictions of the numbers of ice particles expected to form.

The ratio of the TDFR estimates of ice concentrations to that of the singular description, for the various scenarios tested in this work, is less than a factor of 3 both during cooling periods and after isothermal periods. This factor is relatively small in comparison with the strong dependence of INPs on temperature: a factor of 3 variation corresponds to about $2{ }^{\circ} \mathrm{C}$ change in temperature near $-10^{\circ} \mathrm{C}$ and to a $1{ }^{\circ} \mathrm{C}$ change near $-5^{\circ} \mathrm{C}$. The factor 3 is also small in comparison to the variability of INP spectra in the atmosphere. If the additional complexities due to parcel mixing, secondary ice particle generationt and other processes are considered, the effects examined in this paper are clearly of secondary importance.

It may be concluded that immersion freezing can be reasonably represented in cloud models using the singular description. A correction for the cooling-rate dependence can be made with fairly solid support for its magnitude as given by Eq. (5). A further factor of 1 to 3 increase in ice concentrations for clouds that remain isothermal for periods of time is also reasonable on the basis of results here presented, but this factor is more uncertain due to the small number of relevant laboratory experiments.

The predictions of the TDFR model are dependent on the applicability of various parameters. Most important are the $K(T)$ and $k(T)$ functions. The values here used for $\xi, p$ and $q$ are known only for a very limited range of temperatures and INP types. All of these parameters need to be determined with special emphasis on warmer temperatures $\left(T>-15^{\circ} \mathrm{C}\right)$; such tests can be conducted using the droplet array technology. While the impacts of better determinations of these parameters on cloud models can be expected to be minor, the relevant experiments can be of importance for the overall understanding of ice nucleation processes.

The effects just described were derived using the assumption that cloud liquid water content alone is a prime descriptor for the number of ice particles to form via immersion nucleation per unit air volume. This is overly simple due to limited understanding of the transfer of INPs to droplets and drops within clouds. In view of those problems, and the as yet unexplored relationship between measured INP concentrations in air and in cloud water or precipitation, the results here given offer a reasonable first estimate. The main benefit from this work is the insight gained into the process of freezing nucleation in clouds. The time-dependent factors used in the TDFR model lend themselves to being incorporated into more detailed cloud models. 
Table 3. Nomenclature.

\begin{tabular}{|c|c|}
\hline$A$ & Constant in Eq. (1); $\mathrm{g}^{-1}$ \\
\hline$B$ & Dimensionless constant in Eq. (1) \\
\hline$L, L_{S}$ & Cloud liquid water content in $\mathrm{g} \mathrm{m}^{-3}$ and its value at $T_{S}$ \\
\hline$K(T)$ & Cumulative concentration of INPs active at temperatures above $T$ per unit mass of water; $\mathrm{g}^{-1}$ \\
\hline$k(T)$ & Derivative of $K(T) ; \mathrm{g}^{-1}{ }^{\circ} \mathrm{C}^{-1}$ \\
\hline$n$ & Number of nucleation events per unit mass of water; $g^{-1}$ \\
\hline$n_{s}$ & The value of $n$ when the parcel arrives at the isothermal level \\
\hline$\Delta n_{0}$ & Increase $n$ during the isothermal period for $w_{0}$ \\
\hline$N$ & Number concentration of ice particles in the air parcel; $\mathrm{m}^{-3}$ \\
\hline$N_{s}$ & Concentration of ice particles when the parcel arrives at the isothermal level; $\mathrm{m}^{-3}$ \\
\hline$N_{\mathrm{tdfr}}$ & Concentration of ice particles at the isothermal level as $t \rightarrow \infty ; \mathrm{m}^{-3}$ \\
\hline$p, p_{1}$ & Constant in Eq. (6) and its value for $w=1{ }^{\circ} \mathrm{Cmin}^{-1}$ \\
\hline$q, q_{1}$ & Constant in Eq. (6) in $\min ^{-1}$, and its value for $w=1{ }^{\circ} \mathrm{Cmin}^{-1}$ \\
\hline$r_{S}$ & Ratio of ice concentration after a long isothermal period to the predicted value from the singular description \\
\hline$r_{t}$ & Ratio of ice concentrations after a long isothermal period to that when the parcel ascent ends \\
\hline$R(t)$ & Rate of increase nucleation events per unit mass of cloud water; $\mathrm{g}^{-1} \min ^{-1}$ \\
\hline$R_{\mathrm{S}}$ & $\begin{array}{l}\text { Value of } R(t) \text { just prior to the air parcel's arrival at the isothermal level } T_{S} \text {, i.e., during the last instant of cooling } \\
\text { of the parcel }\end{array}$ \\
\hline$t$ & Time; min \\
\hline$T$ & Temperature in ${ }^{\circ} \mathrm{C}$ \\
\hline$T_{S}$ & Temperature at the end of the parcel's ascent; ${ }^{\circ} \mathrm{C}$ \\
\hline$v_{\text {up }}$ & Vertical velocity; $\mathrm{ms}^{-1}$ \\
\hline$w, w_{0}$ & Cooling rate in ${ }^{\circ} \mathrm{C} \mathrm{min}-1$ and a reference value $w_{0}=1^{\circ} \mathrm{C} \mathrm{min}^{-1}$ \\
\hline$\xi$ & Constant in Eq. (5) \\
\hline
\end{tabular}

Acknowledgements. J. R. Snider acknowledges support from NSF grant AGS1034858. Helpful comments by the reviewers are appreciated.

Edited by: T. Garrett

\section{References}

Barahona, D. and Nenes, A.: Parameterizing the competition between homogeneous and heterogeneous freezing in ice cloud formation - polydisperse ice nuclei, Atmos. Chem. Phys., 9, 59335948, doi:10.5194/acp-9-5933-2009, 2009.

Chen, J.-P., Hazra, A., and Levin, Z.: Parameterizing ice nucleation rates using contact angle and activation energy derived from laboratory data, Atmos. Chem. Phys., 8, 7431-7449, doi:10.5194/acp-8-7431-2008, 2008.

de Boer, G., Hashino, T., and Tripoli, G. J.: Ice nucleation through immersion freezing in mixed-phase stratiform clouds: theory and numerical simulations, Atmos. Res., 96, 315-324, doi:10.1016/j.atmosres.2009.09.012, 2010.

DeMott, P. J., Prenni, A. J., Liu, X., Kreidenweis, S. M., Petters, M. D., Twohy, C. H., Richardson, M. S., Eidhammer, T., and Rogers, D. C.: Predicting global atmospheric ice nuclei distributions and their impacts on climate, P. Natl. Acad. Sci. USA, 107, 11217-11222, doi:10.1073/pnas.0910818107, 2010.

DeMott, P. J., Möhler, O., Stetzer, O., Vali, G., Levin, Z., Petters, M. D., Murakami, M., Leisner, T., Bundke, U., Klein, H., Kanji, Z. A., Cotton, R., Jones, H., Benz, S., Brinkmann, M., Rzesanke, D., Saathoff, H., Nicolet, M., Saito, A., Nillius, B.,
Bingemer, H., Abbatt, J., Ardon, K., Ganor, E., Georgakopoulos, D. G., and Saunders, C.: Resurgence in ice nuclei measurement research, B. Am. Meteorol. Soc., 92, 1623-1635, doi:10.1175/2011bams3119.1, 2011.

Diehl, K. and Wurzler, S.: Heterogeneous drop freezing in the immersion mode: model calculations considering soluble and insoluble particles in the drops, J. Atmos. Sci., 61, 2063-2072, 2004.

Diehl, K. and Wurzler, S.: Air parcel model simulations of a convective cloud: bacteria acting as immersion ice nuclei, Atmos. Environ., 44, 4622-4628, doi:10.1016/j.atmosenv.2010.08.003, 2010.

Eidhammer, T., DeMott, P. J., Prenni, A. J., Petters, M. D., Twohy, C. H., Rogers, D. C., Stith, J., Heymsfield, A., Wang, Z., Pratt, K. A., Prather, K. A., Murphy, S. M., Seinfeld, J. H., Subramanian, R., and Kreidenweis, S. M.: Ice initiation by aerosol particles: measured and predicted ice nuclei concentrations versus measured ice crystal concentrations in an orographic wave cloud, J. Atmos. Sci., 67, 2417-2436, 2010.

Herbert, R. J., Murray, B. J., Whale, T. F., Dobbie, S. J., and Atkinson, J. D.: Representing time-dependent freezing behaviour in immersion mode ice nucleation, Atmos. Chem. Phys. Discuss., 14, 1399-1442, doi:10.5194/acpd-14-1399-2014, 2014.

Hiranuma, N., Augustin-Bauditz, S., Bingemer, H., Budke, C., Curtius, J., Danielczok, A., Diehl, K., Dreischmeier, K., Ebert, M., Frank, F., Hoffmann, N., Kandler, K., Kiselev, A., Koop, T., Leisner, T., Möhler, O., Nillius, B., Peckhaus, A., Rose, D., Weinbruch, S., Wex, H., Boose, Y., DeMott, P. J., Hader, J. D., Hill, T. C. J., Kanji, Z. A., Kulkarni, G., Levin, E. J. T., McCluskey, C. S., Murakami, M., Murray, B. J., Niedermeier, D., Petters, M. D., O’Sullivan, D., Saito, A., Schill, G. P., Tajiri, T., Tolbert, M. A., Welti, A., Whale, T. F., Wright, T. P., and Ya- 
mashita, K.: A comprehensive laboratory study on the immersion freezing behavior of illite NX particles: a comparison of seventeen ice nucleation measurement techniques, Atmos. Chem. Phys. Discuss., 14, 22045-22116, doi:10.5194/acpd-14-220452014, 2014.

Hoose, C., Kristjánsson, J. E., Chen, J.-P., and Hazra, A.: A classical-theory-based parameterization of heterogeneous ice nucleation by mineral dust, soot, and biological particles in a global climate model, J. Atmos. Sci., 67, 2483-2503, 2010.

IPCC: Climate Change 2013: The Physical Science Basis. Contribution of Working Group I to the Fifth Assessment Report of the Intergovernmental Panel on Climate Change. Edited by: Stocker, T. F., Qin, D., Plattner, G.-K., Tignor, M., Allen, S. K., Boschung, J., Nauels, A., Xia, Y., Bex, V., and Midgley, P. M., Cambridge University Press, Cambridge, United Kingdom and New York, NY, USA, 1535, 2013.

Joly, M., Amato, P., Deguillaume, L., Monier, M., Hoose, C., and Delort, A.-M.: Quantification of ice nuclei active at near $0{ }^{\circ} \mathrm{C}$ temperatures in low-altitude clouds at the Puy de Dôme atmospheric station, Atmos. Chem. Phys., 14, 8185-8195, doi:10.5194/acp-14-8185-2014, 2014.

Knopf, D. A. and Alpert, P. A.: A water activity based model of heterogeneous ice nucleation kinetics for freezing of water and aqueous solution droplets, Faraday Disc., 165, 513-534, doi:10.1039/c3fd00035d, 2013.

Khvorostyanov, V. I. and Curry, J. A.: A new theory of heterogeneous ice nucleation for application in cloud and climate models, Geophys. Res. Lett., 27, 4081-4084, 2000.

Liu, X. H. and Penner, J. E.: Ice nucleation parameterization for global models, Meteorol. Z., 14, 499-514, 2005.

Lohmann, U. and Diehl, K.: Sensitivity Studies of the Importance of Dust Ice Nuclei for the Indirect Aerosol Effect on Stratiform Mixed-Phase Clouds, J. Atmos. Sci., 63, 968-982, 2006

Morales Betancourt, R., Lee, D., Oreopoulos, L., Sud, Y. C., Barahona, D., and Nenes, A.: Sensitivity of cirrus and mixed-phase clouds to the ice nuclei spectra in McRAS-AC: single column model simulations, Atmos. Chem. Phys., 12, 10679-10692, doi:10.5194/acp-12-10679-2012, 2012.

Muhlbauer, A. and Lohmann, U.: Sensitivity studies of aerosolcloud interactions in mixed-phase orographic precipitation, J. Atmos. Sci., 66, 2517-2538, doi:10.1175/2009jas3001.1, 2009.

Murray, B. J., Broadley, S. L., Wilson, T. W., Atkinson, J. D., and Wills, R. H.: Heterogeneous freezing of water droplets containing kaolinite particles, Atmos. Chem. Phys., 11, 4191-4207, doi:10.5194/acp-11-4191-2011, 2011.

Murray, B. J., O’Sullivan, D., Atkinson, J. D., and Webb, M. E.: Ice nucleation by particles immersed in supercooled cloud droplets, Chem. Soc. Rev., 41, 6519-6554, doi:10.1039/c2cs35200a, 2012.

Niedermeier, D., Ervens, B., Clauss, T., Voigtländer, J., Wex, H., Hartmann, S., and Stratmann, F.: A computationally efficient description of heterogeneous freezing: A simplified version of the soccer ball model, Geophys. Res. Lett., 41, doi:10.1002/2013GL058684, 2014.

Niemand, M., Möhler, O., Vogel, B., Vogel, H., Hoose, C., Connolly, P., Klein, H., Bingemer, H., DeMott, P., Skrotzki, J., and Leisner, T.: A particle-surface-area-based parameterization of immersion freezing on desert dust particles, J. Atmos. Sci., 69, 3077-3092, doi:10.1175/jas-d-11-0249.1, 2012.
Paukert, M. and Hoose, C.: Modeling immersion freezing with aerosol-dependent prognostic ice nuclei in Arctic mixedphase clouds, J. Geophys. Res. Atmos., 119, 9073-9092, doi:10.1002/2014JD021917, 2014.

Peng, L., Snider, J. R., and Wang, Z.: Ice Crystal Concentrations in Wave Clouds: dependencies on Temperature, $D>$ $0.5 \mu \mathrm{m}$ Aerosol Particle Concentration and Duration of Cloud Processing, Atmos. Chem. Phys. Discuss., 14, 26591-26618, doi:10.5194/acpd-14-26591-2014, 2014.

Phillips, V. T. J., DeMott, P. J., and Andronache, C.: An empirical parameterization of heterogeneous ice nucleation for multiple chemical species of aerosol, J. Atmos. Sci., 65, 2757-2783, 2008.

Phillips, V. T. J., Demott, P. J., Andronache, C., Pratt, K. A., Prather, K. A., Subramanian, R., and Twohy, C.: Improvements to an empirical parameterization of heterogeneous ice nucleation and its comparison with observations, J. Atmos. Sci., 70, 378409, doi:10.1175/jas-d-12-080.1, 2012.

Sear, R. P.: Quantitative studies of crystal nucleation at constant supersaturation: experimental data and models, Cryst. Eng. Comm., 16, 6506-6522, doi:10.1039/C4CE00344F, 2014.

Vali, G.: Quantitative evaluation of experimental results on the heterogeneous freezing nucleation of supercooled liquids, J. Atmos. Sci., 28, 402-409, 1971.

Vali, G.: Freezing nucleus content of hail and rain in NE Colorado, Meteor. Mon., 38, 93-105, 1978.

Vali, G.: Freezing rate due to heterogeneous nucleation, J. Atmos. Sci., 51, 1843-1856, 1994.

Vali, G.: Interpretation of freezing nucleation experiments: singular and stochastic; sites and surfaces, Atmos. Chem. Phys., 14, 5271-5294, doi:10.5194/acp-14-5271-2014, 2014.

Wang, B. and Knopf, D. A.: Heterogeneous ice nucleation on particles composed of humic-like substances impacted by $\mathrm{O}(3)$, J. Geophys. Res.-Atmos., 116, D03205, doi:10.1029/2010jd014964, 2011.

Wang, Y., Liu, X., Hoose, C., and Wang, B.: Different contact angle distributions for heterogeneous ice nucleation in the Community Atmospheric Model version 5, Atmos. Chem. Phys., 14, 1041110430, doi:10.5194/acp-14-10411-2014, 2014.

Wright, T. P. and Petters, M. D.: The role of time in heterogeneous freezing nucleation, J. Geophys. Res.-Atmos., 118, 3731-3743, doi:10.1002/jgrd.50365, 2013.

Wright, T. P., Petters, M. D., Hader, J. D., Morton, T., and Holder, A. L.: Minimal cooling rate dependence of ice nuclei activity in the immersion mode, J. Geophys. Res.-Atmos., 118, 1-9, doi:10.1002/jgrd.50810, 2013.

Yang, F., Ovchinnikov, M., and Shaw, R. A.: Minimalist model of ice microphysics in mixed-phase stratiform clouds, Geophys. Res. Lett., 40, 3756-3760, doi:10.1002/grl.50700, 2013.

Zhang, K., Liu, X., Wang, M., Comstock, J. M., Mitchell, D. L., Mishra, S., and Mace, G. G.: Evaluating and constraining ice cloud parameterizations in CAM5 using aircraft measurements from the SPARTICUS campaign, Atmos. Chem. Phys., 13, 4963-4982, doi:10.5194/acp-13-4963-2013, 2013. 